CLINICAL CASE

\title{
Extragonadal germ cell tumor with testicular "burned-out" phenomenon
}

\author{
Óscar Ulloa-Ortiz, Raúl Garza-Garza², Guillermo Hernán Martínez¹, María Guadalupe Moreno-Treviño, \\ María Guadalupe Treviño-Alanís ${ }^{1}$ and Gerardo Rivera-Silva ${ }^{1 *}$ \\ ${ }^{1}$ Division of Health Sciences, Universidad de Monterrey, San Pedro Garza García; ${ }^{2}$ Hospital Christus Muguerza, Monterrey. N.L., Mexico
}

\begin{abstract}
The phenomenon of "burned-out" in an extragonadal germ cell tumor is characterized by regression of testicular tumor. This condition is rare and particular. We report the case of a 52-year-old male with left flank pain that radiated to external genitalia. Physical examination showed a painless and hard mass in the left flank; also a mass in left testicle. Abdominal computed tomography revealed an isodense and homogeneous mass located in retroperitoneal area below the left renal artery and above the common iliac artery. Histological analysis of tumor retroperitoneal reported a germinoma; while testicular atrophy and fibrosis was identified. These types of tumors are surgically treated with chemotherapy and / or radiotherapy and the prognosis is good.
\end{abstract}

Key words: Seminoma. Testicle. Burned-out phenomenon.

Available online: 19-12-2017 Gac Mex Oncol. 2017;16(5):299-302

www.gamo-smeo.com 1665-9201 / ( 2017 Sociedad Mexicana de Oncología. Published by Permanyer México. This is an Open Access article under the terms of the CC BY-NC-ND license (http://creativecommons.org/licenses/by-nc-nd/4.0/). 


\section{Introduction}

The most common testicular neoplasm is germ cell tumor, which accounts for $95 \%$ of cases, and is classified as seminoma and non-seminomatous germ cell tumor. It occurs in men with a mean age of 40 years, and patients typically present with a painless or vaguely painful mass in the testes. Its prognosis is good, with 5 -year survival higher than $95 \%$. Recurrence has been shown to occur after chemotherapy in the form of residual masses, commonly localized in the retroperitoneum 1 .

Extragonadal germ cell tumors are rare, and its localization, in order of frequency, is: mediastinum, retroperitoneum, sacrococcygeal region and pituitary and pineal glands ${ }^{2,3}$. These tumors are considered to be metastatic when they stem from an evident or occult gonadal cancer².

The case is presented of a 52-year old patient diagnosed with retroperitoneal extragonadal germinoma who underwent orchiectomy and chemotherapy, which resulted in significant reduction of the germinoma.

\section{Clinical case}

This is the case of a 52-year old male with pain in the left renal fossa that irradiated to the iliac fossa and ipsilateral testicle over the previous 3 weeks. On physical examination, a painless mass, hard in consistency, was identified in the left renal fossa, with negative Giordano sign. Blood count, blood chemistry and urinalysis were normal. Abdominal X-ray showed a left radiopaque mass at the L1-L3 level (Fig. 1 A), and abdominal computed tomography (CT) confirmed the presence of a large isodense mass located at the retroperitoneal space below the left renal artery and above the left common iliac artery (Figs. $1 B$ and $C$ ). $\alpha$-fetoprotein (AFP) determination was normal, whereas human chorionic gonadotropin (hCG) $\beta$-subunit was reported with a serum level of $9.56 \mathrm{mIU} / \mathrm{mL}(0 \mathrm{mIU} / \mathrm{mL})$. The tumor biopsy showed cell polymorphism, polyhedral cells, with clear cytoplasm without anisocytosis, nuclear anisochromasia and hyperchromasia and mitotic activity; the cells were distributed in nests intermingled with a characteristic desmoplastic stromal background (Fig. 2 A); in addition, immunohistochemical tests were positive for CD-10, vimentin and CD-117 (Fig. 2 B). All these evidences were consistent with seminoma. Testicular ultrasonography revealed the presence of a hypoechogenic focal zone in the left testicle (Fig. 3 A); with the Doppler modality, high blood flow was observed in said region (Fig. 3 B). Left testicular biopsy revealed severe testicular atrophy $(2.4 \mathrm{x}$ $2.2 \times 1.3 \mathrm{~cm}$ ) (Fig. $3 \mathrm{C}$ ), with tubular fibrosis (Fig. $3 \mathrm{D}$ ).

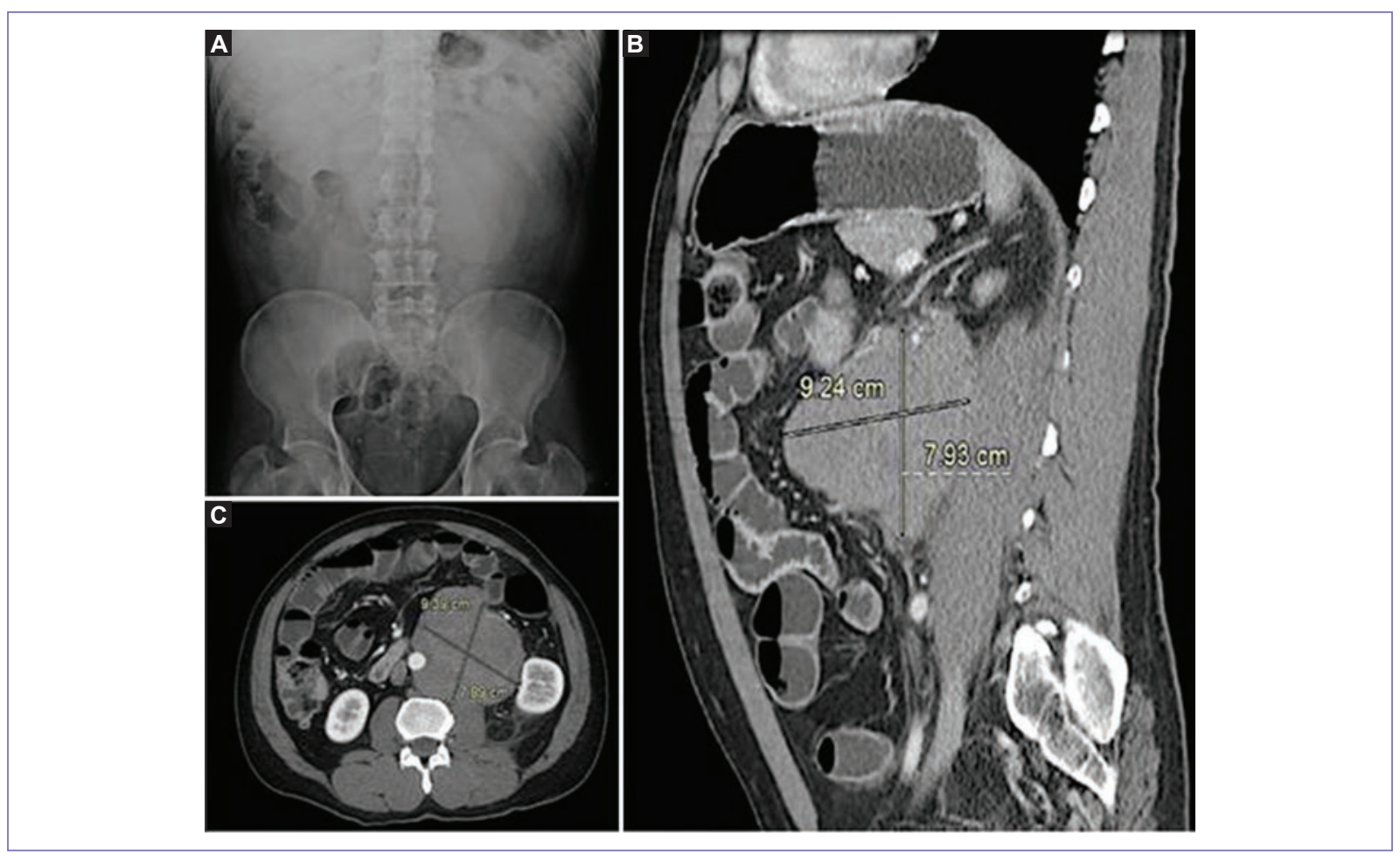

Figure 1. A: abdominal X-ray where a left retroperitoneal mass is observed (L1-L3). Abdominal CT axial plane (B) and sagittal plane (C) showing a left retroperitoneal mass. 


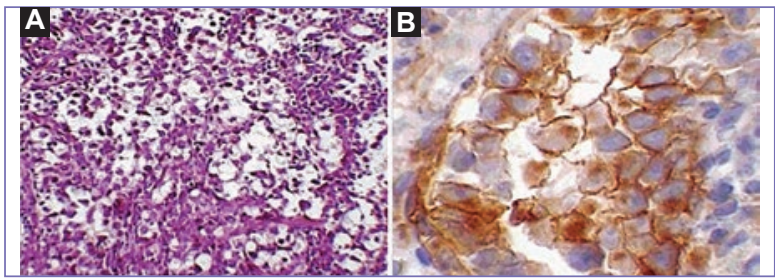

Figure 2. A: microscopic image with cell pleomorphism and cell distribution in nests intermingled with a characteristic desmoplastic stromal background (x10, H\&E). B: immunohistochemistry positive for CD-117 (x40).
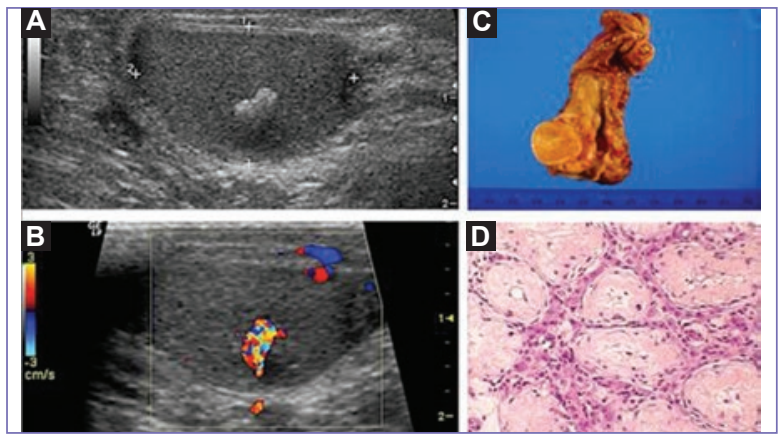

Figure 3. A: left testicle ultrasonography with hypoechogenic focal zone. B: doppler ultrasound image with increased blood flow in the same zone. C: image after left testis orchiectomy showing testicular atrophy. D: histological image with left testicle tubular fibrosis ( $x 40, H \& E)$.

Orchiectomy was carried out and treatment was started with chemotherapy based on bleomycin (30 U intravenously [IV] on days 1, 8 and 15), etoposide (100 mg/m² IV on days 1-5) and cisplatin (20 mg/m² IV on days 1-5), with their respective follow-up based on tumor marker determination (AFP and $\mathrm{hCG}$ ) and abdominal CT scans every 3 weeks. At the conclusion of the antineoplastic therapeutic cycle, abdominal CT showed a significant reduction in tumor size (Fig. 4).

\section{Discussion}

The origin of $95 \%$ of testicle cancers is in germ cell tumors, with the most common being pure seminoma ${ }^{1}$. Risk factors include gonadal dysgenesis, cryptorchidism and family history. Germ cell tumors can be gonadal or extragonadal. Extragonadal germinomas account for $1-5 \%$ of germ cell tumors. One of the causes the occurrence of these tumors can be attributed to might be an aberrant migration of primordial germ cells
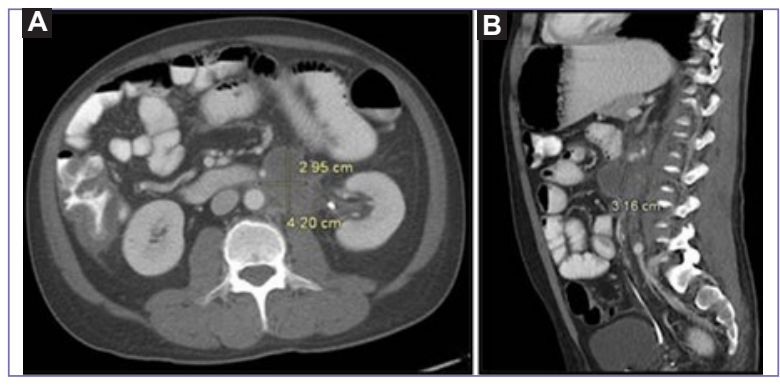

Figure 4. Abdominal CT axial (A) and sagittal (B) plane images with evidence of tumor reduction after treatment was received.

in the midline and a consequent malignant transformation of these cells $\mathbf{s}^{4,5}$, which stem from the proximal epiblast ${ }^{6}$. One of the sites most commonly compromised by this tumors is the retroperitoneum ${ }^{7,8}$. Retroperitoneal germinomas behave as testicular germinonas, which are poorly-differentiated carcinomas. When a germino$\mathrm{ma}$ is found in an extragonadal region, the presence of an occult testicular tumor or the "burned-out" phenomenon should be considered. The latter refers to the existence of an extragonadal germ cell tumor with an intragonadal tumor on regression ${ }^{9,10}$. This situation was what occurred in our reported case, since the testicular tumor biopsy revealed atrophy and fibrosis. Between $60 \%$ and $70 \%$ of retroperitoneal germ cell tumors are caused by metastasis of a testicular germ cell primary cancer, with the rest corresponding to extragonadal germ cell tumors. The risk of metastasis in seminoma is correlated with the size of the primary tumor ${ }^{11}$; nevertheless, if primary testicular cancer is detected, extragonadal germinoma will always be considered to be metastatic.

On the other hand, high levels of AFP and hCG, which are blood tumor markers, guide on germ cell tumors existence, dissemination and relapse ${ }^{12}$. In our patient, elevated hCG levels were found, but AFP was normal, which reinforced the previously mentioned diagnosis. As treatment, left orchiectomy was carried out, in view of the presenting atrophy and the associated risk given the morphologic characteristics ${ }^{13},{ }^{14}$, in addition to bleomycin, etoposide and cisplatin-based chemotherapy ${ }^{15}$, which was able to significantly reduce the size of the germinoma.

\section{Conclusions}

Extragonadal germinomas are malignant neoplasms that can arise from anomalous differentiation of primordial germ cells that failed to correctly migrate in the 
embryonic period; i.e. primary extragonadal tumors. However, the possibility of metastasis of a gonadal germ cell tumor should be also considered, where the germ cell tumor can be occult or else the burned-out phenomenon can be present, where there is regression of the primary gonadal tumor and tumor activity persists as an extragonadal germinoma. The retroperitoneal region is the second most common where this type of tumors are found, with prognosis generally good. The treatment of choice is chemotherapy and orchiectomy when indicated.

\section{Conflict of interests}

The authors declare not having any conflicts of interests.

\section{References}

1. Howitt BE, Berney DM. Tumors of the Testis. Surg Pathol Clin. 2015 8(4):687-716.

2. Shinagare $A B$, Jagannathan JP, Ramaiya $N H$, Hall $M N$, van Den Abbeele AD. Adult extragonadal germ cell tumors. Am J Roentgenol. 2010; 195(4):274-80.
3. Zavala Elizondo A, Martínez Montelongo R, González JE. Tumor extragonadal de células germinales en mediastino: aportación de un caso. Actas Urol Esp. 2008;32(3):357-9.

4. Deb M, Mohanty S, Ananthamurthy A, Garg I, Das K. Atypical extragonadal germ cell tumors. J Indian Assoc Pediatr Surg. 2012;17(1):9-15.

5. Sahoo PK, Mandal PK, Mukhopadhyay S, Basak SN. Burned Out Seminomatous Testicular Tumor with Retroperitoneal Lymph Node Metastasis: A Case Report. Indian J Surg Oncol. 2013;4(4):390-2.

6. Stang A, Trabert B, Wentzensen N, Cook MB, Rusner C, Oosterhuis JW, McGlynn K A. Gonadal and extragonadal germ cell tumours in the United States, 1973-2007. Intern J of Androl. 2012;35(4):616-25.

7. Rahi R, Biswas M, Khanna R, Khanna A K. Extragonadal germ cell tumour. Indian J Surg. 2010;72(2):138-9.

8. Gingu CV, Mihai M, Baston C, et al. Primary retroperitoneal extraembrionario, histopathology and treatment particularities. Rom J Morphol Embryol. 2016;57(3):1045-50.

9. Sahoo PK, Mandal PK, Mukhopadhyay S, Basak SN. Burned Out Seminomatous Testicular Tumor with Retroperitoneal Lymph Node Metastasis: A Case Report. Indian J Surg Oncol. 2013;4(4):390-2.

10. Costanza C. A Case Report of Retroperitoneal Seminoma and Literature Review. J Nucl Med Radiat Ther. 2013;4:1-4.

11. Bernard B, Sweeney C. Diagnosis and Treatment of Testicular Cancer. Surg Pathol. 2015;8(4):717-23.

12. Ruf CG, Khalili-Harbi N, Sachs $\mathrm{S}$, et al. The search for biomarkers of metastatic seminoma. J Urol. 2013;190(3):1046-51.

13. Fedyanin M, Tryakin A, Bulanov A, et al. Effect of the timing of orchiectomy on survival in patients with metastatic germ cell tumors of testis. Urol Oncol. 2014;32(1):32.e27-33.

14. Albers $P$, Albrecht $W$, Algaba F, et al. Guidelines on Testicular Cancer: 2015 Update. Eur Urol. 2015;68(6):1054-68.

15. Miller RE, Dudderidge T, Huddart R, Seckl MJ, Rustin GJS, Christmas TJ. Pathological findings after primary chemotherapy in patients undergoing simultaneous orchidectomy and retroperitoneal lymph node dissection for advanced germ cell tumours. BJU Inter. 2012:111(4 Pt B):E152-7. 